\title{
Accounting Ethics Education: An Interactive Approach
}

\author{
Gwendolen B. White, (E-mail: gwhite@bsu.edu) Ball State University
}

\begin{abstract}
An interactive and technological approach was used to discuss ethics with accounting students. Students responded anonymously to ethics questions using wireless transmitters. The students' responses were shown to the group. A customized DVD of movie scenes from "The Producers" and "Wall Street" and a still picture of Enron's Code of Ethics were used to engage students in discussion. The procedures, the technology, and the benefits of the approach are presented.
\end{abstract}

\section{INTRODUCTION}

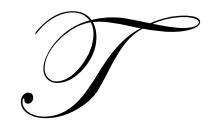

he purpose of this paper is to describe an accounting ethics project that used a technologically interactive approach. In the accounting education literature, there are numerous calls for more interactive and creative approaches to ethics education along with the implementation of technology to accounting education. The current project provides an interactive, creative, and technological method for engaging students in ethics discussions. The method involved students responding anonymously to sensitive ethical questions via a wireless transmitter. Their answers were transmitted to a personal computer and summarized. The technology, personal response system (also known as keypad polling or audience response technology), allows the audience to respond anonymously and receive immediately a summary of the group's responses. In addition, the audience viewed movie scenes on a customized DVD. The scenes depicting moral dilemmas in a business setting were shown with the intent to stimulate discussion about ethical behavior. The customized DVD included a still picture of the cover page of Enron, Inc.'s Code of Ethics (Thesmokinggun.com). This paper includes a discussion of the relevant accounting education literature, the procedures of this project, the technology, the results, and the conclusion.

\section{THE ACCOUNTING EDUCATION LITERATURE}

Over the last 17 years there have been numerous calls for changes in accounting education. Recommendations from various groups, such as The Committee on the Future Structure, Content, and Scope of Accounting Education (The Bedford Committee 1986) of the American Accounting Association (AAA), the large international accounting firms in their "White Paper" (Perspective on Education 1989), and the American Education Change Commission (AECC) 1990, have called for sweeping changes in both the content and delivery of education. In the area of content, these groups have recommended including ethics education in the accounting curriculum. The Bedford Committee was appointed in 1984 by the American Accounting Association's Executive Committee to study the expanding accounting profession and the state of accounting education. The committee concluded that a major reorientation of accounting education was required. Accounting education had not changed for 50 years and was deemed inadequate to meet the needs of future accounting professionals. In their report, The Bedford Committee called for the need to understand the nature and role of ethics. Professional accounting education was called upon to instill the ethical standards and the commitment of a professional. In Perspectives on Education: Capabilities for Success in the Accounting Profession (The White Paper 1989), the then Big 8 accounting firms called for changes in accounting education with more integration of ethics in the curriculum. To show their commitment to the need for change, the accounting firms donated five million dollars to help fund the AECC (Albrecht and Sack 2000). The AECC (1990, 307) provided a focus for those involved in improving accounting education. In their first position statement, the commission states that accounting graduates should "know and understand the ethics of the profession and be able to make value-based judgments " (AECC 1990, 308) and have 
the "ability to identify ethical issues and apply a value-based reasoning system to ethical questions" (AECC 1990, 311).

Since The Bedford Committee and the AECC published their reports, the demand for ethics education has continued. Mintz $(1995,263)$ discussed "the need to expose the students to the values of the profession that underlie moral behavior in accounting." In light of the recent corporate scandals involving the accounting profession (Enron and Arthur Andersen, World Com, Xerox, etc.), an increase in accounting ethics education is warranted (Armstrong et al. 2003). The perceived value of ethics education can also be seen in the education accreditation process. At the April 2003 meeting of The Association to Advance Collegiate Schools of Business (AACSB), the organization voted to include ethics in the curriculum (Mangan 2003). The new standards for business schools accredited by AACSB list ethics as a topic that should be prominent in business courses. Methods of implementation are left to the discretion of the member schools.

Although the need for ethics education has been established, traditional pedagogy is viewed as inadequate. Memorizing rules and codes of conduct are not relevant to effective learning that results in ethical behavior. Fulmer and Cargile (1987) demonstrated that although accounting students who were exposed to the American Institute of Certified Public Accountants' (AICPA) Code of Professional Conduct perceived ethical issues more frequently than other business students given the same information, they did not choose significantly different actions from other business students. The traditional approach where the professor lectures and the student listens is outdated. This passive method of learning is inadequate to engage students. According to the AECC (1990, 309), "students should be active participants in the learning process, not passive recipients of information." Albrecht and Sack (2000) contend that accounting education is not exposing students in the right ways to highly relevant topics such as ethics.

More interactive and creative approaches have been recommended to engage students. As far back as 1986, The Bedford Committee suggested that students should be led to take an active role in the classroom. More recently, Mintz $(1995,262)$ advocated the use of video presentations or role-playing to "involve students in situations where they learn the importance of virtue and/or how to act virtuously." Video presentations of situations depicting moral dilemmas can be used to facilitate discussion. Role-playing can extend discussion with the intent of sensitizing students to ethical situations.

Practitioners and researchers today continue to advocate increasing the ethical sensitivity of accounting students. In a recent monograph, PricewaterhouseCoopers $(2003,5)$ supports this position by saying "All business students must understand that personal integrity is not a choice. It is an obligation for those who serve the public interest." Armstrong et al. (2003) urged accounting researchers to explore ethical character and behavior. They advocate placing a greater emphasis on the three aspects of ethical decision making (sensitivity, motivation, and character) as a means to improve ethical decision-making.

Exploring sensitivity, motivation, and character will require innovation on the part of the professor/researcher. These issues are very personal to individual students and may be difficult to investigate. Interactive communication is one strategy to engage students in a meaningful discussion about their ethical motivation and character. Unfortunately, asking students to answer sensitive ethical questions in a public arena may pose problems. Some students may be reluctant to discuss past unethical behavior. To overcome this problem, the current project was designed to provide anonymity to the individual participants to allow them to answer honestly to sensitive ethical questions.

\section{PROCEDURES OF THE PROJECT}

Twenty-four members of the local chapter of Beta Alpha Psi and one professor participated in a professional development seminar to discuss ethics. At the beginning of the seminar each participant was given a wireless transmitter to respond to ethics questions that appeared on a projector screen. Before the questions were projected, a segment from Joseph Levine's motion picture "The Producers" was shown. The scene depicted a Broadway producer persuading his accountant to help defraud investors. The producer coerced the accountant into participating in the fraudulent scheme. 
After the movie segment was shown, ethics questions appeared on the screen (Exhibit 1). The software used to record the responses was set to receive responses for two minutes for each question. After two minutes, the responses were summarized and displayed on the screen for the group to view. Participants were given the opportunity to comment on the group's responses. Midway through the questions, two segments from Edward Pressman's motion picture "Wall Street" were shown. The first scene involved a powerful, unscrupulous businessman enticing a young, inexperienced stock analyst to commit illegal acts. Although the analyst protested initially by saying he could lose his license, the businessman lured the analyst with promises of enormous wealth. The second scene depicted the stock analyst requesting insider information from an attorney who had been his friend in college. When the attorney raised concerns about the legality of the request, the analyst assured his friend that everyone was "doing it these days." After these two scenes were shown, more questions were displayed, answered, and summarized.

The questions used in the seminar (see Exhibit 1) were in multiple choice and open-ended formats. They included questions about personal motivation for unethical behavior, specific behaviors, sources of their own ethics education, professional codes of ethics, definition of ethics, demographic information, and an evaluation of the seminar. The open-ended questions, demographic information, and seminar evaluation questions were answered on paper and collected at the end of the program.

\section{Exhibit 1: Ethics Questions and Group Response \%}

1. Has anyone asked you to do something that you knew was wrong?
(1) Yes
$83.3 \%$
(2) No
$16.7 \%$

2. Did you feel like it caused great conflict for you?
(1) Yes
$54.2 \%$
(2) No
$45.8 \%$

3. If you have ever done something wrong for someone else, why did you do it? A friend asked you to do something wrong.
(1) Yes
$83.3 \%$
(2) No
$16.7 \%$

4. If you have ever done something wrong for someone else, why did you do it? Someone threatened to harm you if you did not conform.
(1) Yes
$4.2 \%$
(2) No
$95.8 \%$

5. If you have ever done something wrong for someone else, why did you do it? You thought it was a minor wrong.
(1) Yes
$87.5 \%$
(2) No
$12.5 \%$

6. If you have ever done something wrong for someone else, why did you do it? You thought no one would find out.
(1) Yes
$83.3 \%$
(2) No
$16.7 \%$

7. Do you think you know right from wrong?

(1) Always

$16 \%$

(2) Most of the time $84 \%$

(3) Sometimes 0

(4) Seldom 0

(5) Never

0

8. When you are about to learn a new game, what do you ask yourself?

(1) How can I cheat? 0

(2) What are the rules to win? $100 \%$ 
9. Do you try to play by the rules?
(1) Always $32 \%$
(2) Most of the time $56 \%$
(3) Sometimes 0
(4) Seldom 4\%
(5) Never $8 \%$

10. Do you think there is one set of rules that defines right from wrong in all situations?
(1) Yes
(2) No
0
100

11. Where did you learn right from wrong?

You learned from your parents.
(1) Yes
$95.7 \%$
(2) No
$4.3 \%$

12. Where did you learn right from wrong?

You learned in a religious setting.
(1) Yes
$92 \%$
(2) No
$8 \%$

13. Where did you learn right from wrong?

You learned at school.
(1) Yes
$88 \%$
(2) No
$12 \%$

14. What is your definition of ethics?

15. Is ethical conduct essential to a free market economy?
(1) Yes
$75 \%$
(2) No
$25 \%$

16. Should every organization have a code of ethics?
(1) Yes
$88 \%$
(2) No
$12 \%$

17. Do you think Enron had a code of ethics?

(1) Yes $80 \%$

(2) No 20\%

18. Should a Certified Public Accountant (CPA) be concerned about ethics in his/her practice?
(1) Yes
$96 \%$
(2) No
$4 \%$

19. Do CPAs need a written code of ethics?

$\begin{array}{ll}\text { (1) Yes } & 75 \% \\ \text { (2) No } & 25 \%\end{array}$

20. Will rules guide behavior?

(1) People will do what is right whether or not the rules are written. $16 \%$

(2) Rules should not be written but passed on through adequate training. $12 \%$

(3) Rules should be written, and people should be taught how to obey them. $72 \%$

21. What is the CPA trying to do by auditing the financial statements?

(1) Give the readers assurance about the quality of the statements. $80 \%$

(2) Help their client make a profit. $16 \%$

(3) Give the readers assurance about the quality of the statements $4 \%$ and help their client make a profit.

22. Does the auditor need to be independent of the company to give an unbiased opinion on financial statements?
(1) Yes
$80 \%$
(2) No
$20 \%$ 
23. Did you like using the personal response system to answer questions about ethics?
(1) Yes
$92 \%$
(2) No
0
(3) Indifferent
$8 \%$

24. Would you like to participate in other discussions using the same technology?
(1) Yes
$92 \%$
(2) No
$8 \%$

25. If you answered "yes" to \#23 above, state some reasons for your answer.

(See Exhibit 2)

26. If you answered "no" to \#23 above, state some reasons for your answer.

None reported

27. If you have any comments you wish to make about the seminar, please answer here.

(See Exhibit 2)

28. Please answer the following:

a. Are you Male or Female?

$40 \% \quad 60 \%$

b. Age - Average 25 years

c. Class Standing

Juniors 6

Seniors 9

Graduate Students 9

Faculty 1

d. $\quad$ GPA - Average 3.7

e. Previous Ethics Course in college -
(1) Yes $16 \%$
(2) No $\quad 80 \%$
(3) Missing data $4 \%$

29. Did you feel that you could respond honestly using the personal response system?

$\begin{array}{lr}\text { (1) Yes } & 96 \% \\ \text { (2) No } & 4 \%\end{array}$

\section{THE TECHNOLOGY}

A personal response system (keypad polling or audience response system) includes the hardware and software to conduct a meeting or class that requires immediate response and/or interaction from the audience. The system can be set to allow group members to respond anonymously to questions. Responses can be stored in a computer file for further analysis.

Personal response systems have been useful in a variety of situations. In the entertainment industry, many television shows that require audience participation employ similar systems. In business and government settings, decision-making has been facilitated by questionnaires or surveys that can be summarized immediately. For example, on July 20, 2002, a group of 5,000 participants meeting to discuss the planning of the 9/11memorial in New York City used a personal response system (keypad polling) to facilitate their planning process (Schutt 2002). There are numerous commercial firms (e.g., Fleetwood Group, Inc.) that contract with organizations to provide audience response equipment and consultants to act as discussion facilitators. In academia, personal response systems have provided the opportunity for interactive classroom discussions. Professor Barry Rice of Loyola College in Baltimore instituted keypads in his accounting class to get immediate responses to multiple-choice questions and to stimulate his students (Cytron 1998). Burnstein and Lederman (2001), physics professors at the Illinois Institute of Technology, reported a dramatic increase in student participation in their lecture courses when they used the wireless transmitters in their elementary physics courses. 
In addition to the personal response system, movie scenes depicting ethical dilemmas and picture of the cover page of Enron's Code of Ethics (www.smokinggun.com 2002) were used in this project to encourage discussion about ethical motivation, behavior, and codes of conduct. Although the use of movies scenes to illustrate a point in the classroom is not new, the technology to customize these presentations is more available. The author had selected the scenes from movies on commercially prepared DVDs. The media center at the author's university transferred the segments to a custom DVD complete with titles and a menu. The customized DVD allowed for smooth transition between the ethics questions and the video presentations.

\section{THE RESULTS}

The open-ended responses to the evaluation of the seminar (Exhibit 2) were as interesting as the responses to the multiple choice questions about motivation, behavior, and professional codes of ethics (Exhibit 1). In their responses to the open-ended questions, many of the participants reported that they liked the interactive approach, and they appreciated the anonymity that the system allowed. How others in the group responded was of great interest to many of them.

\section{Exhibit 2}

\section{Question 25 - Reasons why participants liked using PRS}

- It's fun to see what others think

- It's interesting. It provides basis for discussion

- It was fairly simple fast and it was kind of interesting to see the percentages in real time

- $\quad$ I enjoyed the activity and the rate of return on the feedback

- It is interesting to see how the other people responded differently from how I do

- I I think it is more confidential

- It was an enjoyable experience. It was a good way to find out how fellow classmates honestly felt about certain situations

- I like to know what other believe and think in certain situations and certain issues

- I I felt I could answer honestly without anyone knowing what my answer was. Also it is something different so more people will be into it

- $\quad$ Anonymous and I thought it was very interesting

- $\quad$ I thought it was interesting to see the results, and efficient. It helped me promote discussion a little

- $\quad$ You get to see the results of the questions right away

- It was interesting to see the answers for the entire group displayed graphically immediately after answering

- I I think the topic of ethics poses some interesting discussions because many times it is a judgement call

- $\quad$ Better than just sitting there listening to someone talk

- I I feel that it helps you pay attention and stay alert. It helps you compare your answers to other students

- The response is fast and anonymous. It is interesting to see everyone's response right after we make it

- I thought it was fairly easy and this way we're not scared to answer the way we truly want to

- It's anonymous, I like that

- I always like to help out. The anonymity is nice

- $\quad$ It was a good way to conduct a survey

- $\quad$ Easy and unbiased

- $\quad$ It was easy to answer and somewhat interesting

Question 27 - Comments about Seminar

- I thought it was interesting. I think having movie clips was a good idea

- $\quad$ Excellent job- really enjoyed the variety of activities- we should use this in class

- It is very interesting. If there are some more real life situation in the question that will be more interesting

- It was electrifying. We should have taken a head count of how many people were participating 
- It was interesting

- I believe a lot of different groups should answer the questions to see the responses. Maybe older vs. younger or men vs. women

- $\quad$ Liked movie clips and answering questions. Very good idea

- $\quad$ This seminar was really informative and fun. Especially since it was interactive

- More discussion would have been interesting but we have a lot of introverts in the program

- $\quad$ Very interesting, I enjoyed participating

- I think it was very educational and interesting. Sometimes I needed more time to read the question

- $\quad$ Very thought provoking. Technology makes it more fun

- $\quad$ It was well run and fun. The discussions it generated were intriguing

\section{CONCLUSION}

The use of the personal response system and the customized DVD achieved the goal of the seminar - to conduct an interactive and technological approach to discussing ethics in accounting. The participants' reactions to the seminar were very positive. They found the wireless transmitters easy to use. Based on the comments and interaction during the seminar, the personal response system would apply to many accounting classes where group interaction is desired. This is particularly true if the professor wants everyone involved.

The author's experience with the system was also very positive. The personal response system was easy to use. It took less than one hour to learn to operate the system (this excludes installation of the software). The system is portable. The software and equipment used in this project were borrowed from the Department of Astronomy and Physics. Since this project was conducted, the author has received a $\$ 2500$ internal university grant to purchase 50 wireless transmitters, personal response software, and two wireless receivers to conduct research on interactive ethics education.

The benefits of using the personal response system are many. For the professor, the system offers an opportunity to create a more dynamic environment in which to teach ethics. Professors can engage their students in discussion about ethical motivation and behavior. The students are more likely to think about what is being discussed because they are active participants. They can feel comfortable about participating because they can maintain their anonymity. The system is also affordable and portable. In the past similar equipment was expensive and usually fixed in one location. It has multiple functions. It can be used to register attendance and provide quizzes with instant grading.

The incorporation of a personal response system addresses many of the concerns and recommendations that have been made over the years to improve accounting education and, in particular, ethics education. It is interactive and technological. The system moves away from the outdated, passive lecture approach to an innovative, dynamic, and technological method.

\section{References}

1. Albrecht, W. S., and R. J. Sack. 2000. Accounting Education: Charting the Course through a Perilous Future, Accounting Education Series, Volume No. 16, Sarasota, FL: American Accounting Association.

2. American Accounting Association, "Committee on the Future Structure, Content, and Scope of Accounting Education" (The Bedford Committee)." 1986. "Future Accounting Education: Preparing for the Expanding Profession." Issues in Accounting Education (spring): 168-195.

3. American Education Change Committee (AECC). 1990. "Objectives of education for accountants: Position statement number one." Issues in Accounting Education (fall): 307-312.

4. Armstrong, M. B., J. E. Ketz, and D. Owsen. 2003. "Ethics Education In Accounting: Moving Toward Ethical Motivation And Ethical Behavior." Journal of Accounting Education

5. Burnstein, R. A. and L. M. Lederman. 2001. "Using Wireless Keypads in Lecture Classes," The Physics Teacher, 39: 8-11. 
6. Cytron, S. 1998. "Leading the Class Into the $21^{\text {st }}$ Century," Journal of Accountancy, June: 56-58.

7. Fleetwood Group, Inc. Retrieved from http://www.replysystems.com/

8. Fulmer and Cargile. 1987. "Ethical Perceptions of Accounting Students: Does Exposure to a Code of Professional Ethics Help?" Issues in Accounting Education, (Fall): 207-219.

9. Levine, J. \& S. Glazier (Producer), \& Brooks, M. (Writer/Director). 1968. The Producers [Motion picture]. United States: Metro Golden Mayer

10. Mangan, K. 2003. "Business-School Accrediting Group Adopts New Standards, Providing More Leeway on Faculty Qualifications," The Chronicles of Higher Education.

11. Mintz, S. M. 1995. "Virtue Ethics and Accounting Education," Issues in Accounting Education, (Fall): 247 $-267$.

12. Pressman, E. (Producer), Weiser, S. (Writer), \& Stone, O. (Writer/Director). 1987. Wall Street [Motion picture]. United States: Twentieth Century Fox

13. PricewaterhouseCoopers. 2003. Educating for the Public Trust - The PricewaterhouseCoopers Position on Accounting Education, Delaware

14. Perspectives on Education: Capabilities for Success in the Accounting Profession (The White Paper). 1989. Arthur Andersen \& Co., Arthur Young, Coopers \& Lybrand, Deloitte Haskins \& Sells, Ernst \& Whinney, Peat Marwick Main \& Co., Price Waterhouse, and Touche Ross, New York, NY.

15. Schutt, D. 2002. Listening to the City: An Event to Remember. Retrieved from www.wisc.edu/improve/ who/2002vol6issue5.pdf

16. Thesmokinggun.com. 2002. Enron, Inc. "Code of Ethics." Retrieved from http://www.thesmokinggun.com/ enron/enronethics1.shtml.

Notes 